\title{
Matsuda-Heck reaction with arenediazonium tosylates in water
}

\author{
Ksenia V. Kutonova ${ }^{1}$, Marina E. Trusova ${ }^{1}$, Andrey V. Stankevich ${ }^{2}$, Pavel S. Postnikov ${ }^{*} 3 \S$ \\ and Victor D. Filimonov ${ }^{1}$
}

\section{Full Research Paper}

\section{Address:}

${ }^{1}$ Department of Biotechnology and Organic Chemistry, National Research Tomsk Polytechnic University, 634050 Tomsk, Russia,

2Laboratory of Materials and Technologies of Liquid Crystal Devices, Institute of Chemistry of New Materials NAS Belarus, 220141, Minsk, Belarus and ${ }^{3}$ Department of General and Inorganic Chemistry, National Research Tomsk Polytechnic University, 634050 Tomsk, Russia

Email:

Pavel S. Postnikov* - postnikov@tpu.ru

* Corresponding author

§ Fax: +7 (3822) 563637

Keywords:

alkyl cinnamates; diazonium salts; Matsuda-Heck reaction;

microwave-assisted synthesis; stilbenes

\begin{abstract}
Beilstein J. Org. Chem. 2015, 11, 358-362.
\end{abstract} doi:10.3762/bjoc. 11.41

Received: 08 January 2015

Accepted: 01 March 2015

Published: 16 March 2015

Associate Editor: I. Marek

(C) 2015 Kutonova et al; licensee Beilstein-Institut. License and terms: see end of document.

\begin{abstract}
\section{Introduction}

Diazonium salts are known as one of the most valuable building blocks in organic synthesis [1]. Today, their most common use is the construction of carbon-carbon bonds in palladiumcatalyzed reactions. Starting with the work of Matsuda's group [2], who used a diazonium salt as a high-reactive electrophile for a Heck reaction, the Matsuda-Heck reaction does require the addition of neither bases nor ligands and is carried out under very mild conditions [3]. Furthermore, diazonium salts are more often prepared from commercially available anilines than from haloarenes or triflates.
\end{abstract}

An environmentally friendly Matsuda-Heck reaction with arenediazonium tosylates has been developed for the first time. A range of alkenes was arylated in good to quantitative yields in water. The reaction is significantly accelerated when carried out under microwave heating. The arylation of haloalkylacrylates with diazonium salts has been implemented for the first time.

Typically, alcohols, THF or DMF are used as solvents for Matsuda-Heck reactions. One of the most rapidly developing trends in organic synthesis is the carrying out of reactions in water following a «Green chemistry» approach [4]. In 2012, examples of the Matsuda-Heck arylation of styrene and acrylic acid esters with arenediazonium tetrafluoroborates in water and catalyzed with in situ formed Pd nanoparticles [5] or agarosesupported Pd nanoparticles [6] have been reported. Superparamagnetic $\mathrm{Pd}-\mathrm{ZnFe}_{2} \mathrm{O}_{4} \mathrm{MNPs}$ have been shown to be effective catalysts for the Matsuda-Heck arylation of styrene and ethyl 
acrylate in water [7]. It is noteworthy that these catalysts are not commercially available and must be synthesized from $\mathrm{Pd}(\mathrm{OAc})_{2}$. Roglands et al. prepared a range of tert-butyl cinnamates and stilbenes from arenediazonium tetrafluoroborates in water with $5 \mathrm{~mol} \%$ of commercial $\mathrm{PdCl}_{2}\left(\mathrm{CH}_{3} \mathrm{CN}\right)_{2}$ as a catalyst. The yields of cinnamates were rather high, while stilbenes were obtained with modest yields [8]. Up to date only one example of a simple palladium diacetate-catalyzed arylation of alkenes by diazonium salts in water has been described by the group of Vallribera [9]. Arenediazonium tetrafluoroborates bearing only electron-donating groups (with the exception of chlorine) were effectively coupled with ethyl and tert-butyl acrylates only, while ethyl vinyl ketone, styrenes, allyl acetate, allyl benzene and methyl vinyl carbinol were rather less reactive under these conditions, and products were obtained with low to modest yields [9].

Previously, we described a novel type of diazonium salt arenediazonium tosylates (ADT), which differ from arenediazonium tetrafluoroborates in their higher stability at a dry state and their good solubility in water [10]. It was also shown that ADT are more reactive than arenediazonium tetrafluoroborates in a iodo- [11] and an azidodediazoniation reaction [12]. Another ADT advantage is their safety against explosion accidents, because their decomposition energy is less than $800 \mathrm{~J} / \mathrm{g}$ $[10,12]$. In this work, we present a fast, environmentally friendly, low palladium loading method of the Matsuda-Heck arylation of the different alkenes with ADT in water under microwave irradiation.

\section{Results and Discussion}

Our preliminary study was dedicated to the optimization of the alkene arylation conditions. Methyl acrylate (1a) was chosen as a model substrate as it is highly reactive in standard Matsuda-Heck reactions. Therefore, a solution of 4-nitrobenzenediazonium tosylate (2a) in water was allowed to react with 1.2 equiv of methyl acrylate (1a) in the presence of $1 \mathrm{~mol} \% \mathrm{Pd}(\mathrm{OAc})_{2}$ at $\mathrm{rt}$, at $75{ }^{\circ} \mathrm{C}$ with standard heating and at $75^{\circ} \mathrm{C}$ based on a microwave-enhanced protocol (Scheme 1, Table 1).

$\begin{aligned} & \text { Table 1: Arylation of methyl acrylate (1a) } \\
& \text { late 2a. Study of reaction conditions. }\end{aligned}$
\begin{tabular}{cccc} 
Entry & $T\left({ }^{\circ} \mathrm{C}\right)$ & $t(\mathrm{~min})$ & Yield of 3aa $(\%)$ \\
\hline 1 & $\mathrm{rt}$ & 80 & 96 \\
2 & 75 & 20 & 94 \\
$3^{\mathrm{a}}$ & 75 & 1 & 97 \\
\hline
\end{tabular}

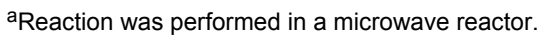

The reaction was carried out at room temperature and methyl 4-nitrocinnamate (3aa) was obtained in 96\% yield after $80 \mathrm{~min}$ (Table 1, entry 1). The increased stability of ADT in organic solvents allowed an increase of the reaction temperature to $75{ }^{\circ} \mathrm{C}$ (Table 1, entry 2) which gave the desired compound in comparable yield in $20 \mathrm{~min}$.

It is well-known that microwave irradiation can significantly reduce the reaction time for a wide range of transformations, including Heck reactions, when compared with standard heating [13]. Thus, the aim of our next experiment was the reduction of the reaction time by using microwave irradiation (Table 1, entry 3). By means of this protocol 3aa was obtained with an almost quantitative yield with a reaction time of only $1 \mathrm{~min}$. Carrying out the reaction with $1 \mathrm{~mol} \%$ of $\mathrm{Pd}(\mathrm{OAc})_{2}$ in water at $75{ }^{\circ} \mathrm{C}$ in a microwave reactor was selected as the best reaction conditions.

To evaluate the scope of this reaction, a variety of arenediazonium tosylates $\mathbf{2 a}-\mathbf{i}$ and a range of alkenes $\mathbf{1 a}-\mathbf{c}$ were used (Scheme 2, Table 2).

Our method displays a general applicability. The arylation of methyl acrylate (1a) was efficient with ADT, substituted by both electron-withdrawing (Table 2, entries 1-3, 7-9) and electron-donating (Table 2, entries 4-6,9) groups and methyl cinnamates were prepared with good to excellent yields and with excellent purity. Two exceptions are the reaction of ADT $\mathbf{2 h}$ (Table 2, entry 9) and $\mathbf{2 i}$ (Table 2, entry 10), which proofed to be less reactive, so that the complete conversion was only

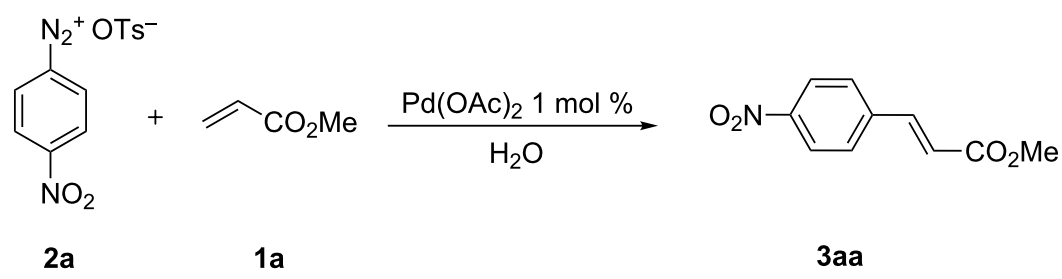




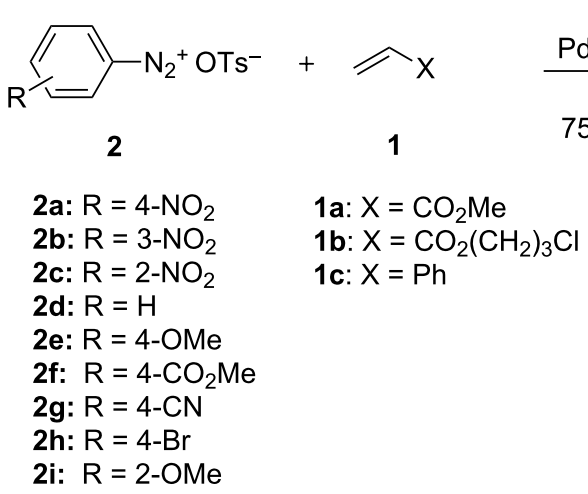

Scheme 2: Arylation of alkenes with ADT.

Table 2: Arylation of alkenes with arenediazonium tosylates in water under microwave heating.

\begin{tabular}{|c|c|c|c|c|}
\hline Entry & 1 & 2 & $T(\min )$ & Yield of $3(\%)^{a}$ \\
\hline 1 & $1 a$ & $2 a$ & 1 & 97 \\
\hline 2 & $1 a$ & $2 b$ & 1 & 92 \\
\hline 3 & $1 a$ & $2 c$ & 1 & 92 \\
\hline 4 & $1 a$ & $2 d$ & 1 & 86 \\
\hline 5 & $1 \mathrm{a}$ & $2 d$ & 120 (16 h [9]) & $84^{\mathrm{b}}(88[9])$ \\
\hline 6 & $1 a$ & $2 e$ & 2 & 96 \\
\hline 7 & $1 a$ & $2 f$ & 1 & 92 \\
\hline 8 & $1 a$ & $2 g$ & 2 & 94 \\
\hline 9 & $1 \mathrm{a}$ & $2 h$ & 5 & $88^{c}$ \\
\hline 10 & $1 a$ & $2 \mathbf{i}$ & 6 & $93^{c}$ \\
\hline 11 & $1 b$ & $2 a$ & 1 & 90 \\
\hline 12 & $1 b$ & $2 b$ & 2 & 72 \\
\hline 13 & $1 b$ & $2 g$ & 3 & 69 \\
\hline 14 & $1 c$ & $2 a$ & 10 & 67 \\
\hline 15 & $1 c$ & $2 a$ & $14 \mathrm{~h}$ & $42^{b}$ \\
\hline 16 & 1c & $2 b$ & 10 & 52 \\
\hline 17 & $1 \mathrm{c}$ & $2 e$ & 50 & 50 \\
\hline 18 & $1 c$ & $2 f$ & 15 & 65 \\
\hline
\end{tabular}

aReaction conditions: ADT (1 mmol), alkene (1.2 mmol), $\mathrm{Pd}(\mathrm{OAc})_{2}$ $1 \mathrm{~mol} \%$; isolated yield for pure products; breaction was performed under rt; ${ }^{\mathrm{C}} \mathrm{Pd}(\mathrm{OAc})_{2} 2.5 \mathrm{~mol} \%$ were used.

achieved with $2.5 \mathrm{~mol} \%$ of palladium diacetate. No side-products were detected including phenols (as monitored by GC-MS and HPLC). The latter are often formed if diazonium salts take part in reactions in water and under heating. It is noteworthy that solid methyl cinnamates 3aa-3ac, 3ae-3ah can be filtered and purified by simply washing them with water and do not need an additional purification in the absence of organic solvents.

The reaction of ADT with 3-chloropropyl acrylate (1b) allows the obtainment of valuable 3 -chloropropyl cinnamates (Table 2, entries 11-13) with good to excellent yields. Haloalkyl cinnamates are important building blocks in the synthesis of nitric oxide-donor hybrid drugs for the treatment of cardiovascular disease and cancer [14-17]. Previously, haloalkyl cinnamates were synthesized by the $O$-alkylation of cinnamic acids with dihaloalkanes or haloalkyl alcohols $[14,16,18]$ or by the ring opening of tetrahydrofuran with cinnamic acid anhydrides or haloanhydrides, catalyzed by yttrium trichloride [19], titanium chloride, stannic chloride or allylsamarium bromide [20] under harsh conditions with modest yields. The synthesized 3-chloropropyl cinnamates 3ba, 3bb, 3bg were not reported before.

Styrene (1c) is less reactive than acrylates in Heck-type reactions. Notwithstanding, a range of stilbenes was synthesized stereoselectively with good yields and purity (Table 2, entries 14-18).

\section{Conclusion}

In summary, a fast, simple, eco-friendly Heck arylation protocol in water with stable, safe and water-soluble arenediazonium tosylates is described. It was shown that in most cases the microwave irradiation significantly decreases the reaction time to several minutes. High yields for electron-deficient alkenes and moderate yields for electron-rich alkenes were obtained. The reaction has a broad range and gives the desired products with a high purity.

\section{Experimental}

All starting materials were ACS grade and were employed without further purification. Arenediazonium tosylates 2 were prepared by a previously described method [10]. HPLC analysis was conducted with an Agilent 1200 instrument fitted with an Eclipse Plus C18 column $(5 \mu \mathrm{m}, 4.6 \times 150 \mathrm{~mm})$ and a UV detector. GC-MS (EI) measurements were obtained with an Agilent 7890/5975C instrument. ${ }^{1} \mathrm{H},{ }^{13} \mathrm{C}$ NMR and IR spectra 
were recorded on a Bruker Avance 300 and a Perkin Elmer BXII, respectively. Melting points were obtained with a melting point system MP50, Mettler Toledo (values are given uncorrected). HPLC-MS measurements were obtained with a Thermo Scientific DFS High Resolution GC-MS. Microwave heating was carried out at $2455 \mathrm{MHz}$ with a CEM Discover System (model 908010) from MATTHEWS, NC (USA).

\section{Arylation of alkenes 1 with ADT 2 under microwave irradiation: general procedure}

To the solution of ADT $(1 \mathrm{mmol})$ in $\mathrm{H}_{2} \mathrm{O}(10 \mathrm{~mL})$ at room temperature were added alkene $(1.2 \mathrm{mmol})$ and $\mathrm{Pd}(\mathrm{OAc})_{2}$ $(0.010 \mathrm{mmol}, 2.3 \mathrm{mg})$. The reaction mixture was heated to $75{ }^{\circ} \mathrm{C}$ under stirring by using a microwave reactor in openvessel mode with a power of $50 \mathrm{~W}$. The conversion of ADT was monitored every minute with a diazonium test with 2-naphthol. When the diazonium test was negative, the reaction mixture was cooled and in the case of solid methyl cinnamates 3aa-3ac and 3ae-3ah the product was filtered, washed with water $(25 \mathrm{~mL})$, and dried on air. Otherwise the reaction mixture was extracted twice with dichloromethane $(10 \mathrm{~mL})$, the organic layer was filtered through a pad of silica and dried over anhydrous $\mathrm{Na}_{2} \mathrm{SO}_{4}$. The solvent was removed in a rotary evaporator under reduced pressure and the crude product was purified by flash chromatography.

3-Chloropropyl (E)-3-(4-nitrophenyl)acrylate (3ba): Yield $90 \%, 0.90 \mathrm{mmol}$, pale yellow solid, mp $86{ }^{\circ} \mathrm{C}$; ${ }^{1} \mathrm{H}$ NMR $\left(300 \mathrm{MHz}, \mathrm{DMSO}-d_{6}\right) \delta 8.23(\mathrm{~d}, J=8.7 \mathrm{~Hz}, 2 \mathrm{H}), 8.00(\mathrm{~d}, J=$ $8.7 \mathrm{~Hz}, 2 \mathrm{H}), 7.77(\mathrm{~d}, J=16.2 \mathrm{~Hz}, 1 \mathrm{H}), 6.84(\mathrm{~d}, J=16.2 \mathrm{~Hz}$, $1 \mathrm{H}), 4.28(\mathrm{t}, 2 \mathrm{H}), 3.76(\mathrm{t}, 2 \mathrm{H}), 2.11(\mathrm{~m}, 2 \mathrm{H}) ;{ }^{13} \mathrm{C} \mathrm{NMR}$ $\left(75 \mathrm{MHz}, \mathrm{DMSO}-d_{6}\right) \delta 165.6,148.0,142.4,140.4,129.5$, 123.9, 122.2, 61.4, 41.9, 31.1; EI-MS m/z: 269 [M] ; HRMS $m / z$ : calcd for $\mathrm{C}_{12} \mathrm{H}_{12} \mathrm{NO}_{4} \mathrm{Cl}, 269.0449$; found, 269.0452 .

3-Chloropropyl (E)-3-(3-nitrophenyl)acrylate (3bb): Yield $72 \%, 0.72 \mathrm{mmol}$, pale yellow solid, mp $75{ }^{\circ} \mathrm{C} ;{ }^{1} \mathrm{H}$ NMR (300 MHz, DMSO- $\left.d_{6}\right) \delta 8.54(\mathrm{~s}, 1 \mathrm{H}), 8.24-8.17(\mathrm{~m}, 2 \mathrm{H}), 7.80$ (d, $J=16.2 \mathrm{~Hz}, 1 \mathrm{H}), 7.69(\mathrm{~m}, 1 \mathrm{H}), 6.84(\mathrm{~d}, J=16.2 \mathrm{~Hz}, 1 \mathrm{H})$, $4.27(\mathrm{t}, 2 \mathrm{H}), 3.77(\mathrm{t}, 2 \mathrm{H}), 2.11(\mathrm{~m}, 2 \mathrm{H}) ;{ }^{13} \mathrm{C} \mathrm{NMR}(75 \mathrm{MHz}$, DMSO- $\left.d_{6}\right) \delta 165.7,148.2,142.2,135.9,134.1,130.4,124.6$, $123.0,120.9,61.3,41.9,31.2$; HRMS $\mathrm{m} / z$ : calcd. for $\mathrm{C}_{12} \mathrm{H}_{12} \mathrm{NO}_{4} \mathrm{Cl}$, 269.0449; found, 269.0456.

3-Chloropropyl (E)-3-(4-cyanophenyl)acrylate (3bg): Yield 69\%, $0.69 \mathrm{mmol}$, white solid, mp $58{ }^{\circ} \mathrm{C} ;{ }^{1} \mathrm{H}$ NMR $(300 \mathrm{MHz}$, DMSO-d $d_{6} \delta 7.93-7.85(\mathrm{~m}, 4 \mathrm{H}), 7.74(\mathrm{~d}, J=16.2 \mathrm{~Hz}, 1 \mathrm{H}), 6.80$ $(\mathrm{d}, J=16.2 \mathrm{~Hz}, 1 \mathrm{H}), 4.27(\mathrm{t}, 2 \mathrm{H}), 3.75(\mathrm{t}, 2 \mathrm{H}), 2.11(\mathrm{~m}, 2 \mathrm{H})$; ${ }^{13} \mathrm{C}$ NMR $\left(75 \mathrm{MHz}\right.$, DMSO- $\left.d_{6}\right) \delta 165.6,142.6,138.5,132.7$, 129.0, 121.4, 118.5, 112.3, 61.3, 41.8, 31.1; HRMS $m / z$ : calcd. for $\mathrm{C}_{13} \mathrm{H}_{12} \mathrm{NO}_{2} \mathrm{Cl}, 249.0551$; found, 249.0548 .

\section{Supporting Information}

\section{Supporting Information File 1}

Additional experimental data.

[http://www.beilstein-journals.org/bjoc/content/

supplementary/1860-5397-11-41-S1.pdf]

\section{Acknowledgements}

This research was supported by the RFBR grant No. 14-0300743. VF acknowledges the Scientific Program «Nauka» No. 3.1344.2014. KK acknowledges the Scientific Program «Nauka» No. 11.9179.2014. We thank S. Bräse for the discussion and the helpful advice in the prepraration of this manuscript.

\section{References}

1. Bräse, S.; Schroen, M. Angew. Chem., Int. Ed. 1999, 38, 1071-1073. doi:10.1002/(SICI)1521-3773(19990419)38:8<1071::AID-ANIE1071>3. $0 . C O ; 2-9$

2. Kikukawa, K.; Nagira, K.; Wada, F.; Matsuda, T. Tetrahedron 1981, 37, 34-36. doi:10.1016/S0040-4020(01)97711-7

3. Roglands, A.; Pla-Quintana, A.; Moreno-Marias, M. Chem. Rev. 2006, 106, 4622-4643. doi:10.1021/cr0509861

4. Bräse, S.; de Meijere, A. Cross-Coupling of Organyl Halides with Alkenes - The Heck Reaction. In Metal-Catalyzed Cross-Coupling Reactions and More; de Meijere, A.; Bräse, S.; Oestreich, M., Eds.; Wiley-VCH: Weinheim, 2014; pp 533-664.

5. Gaikwad, D. S.; Pore, D. M. Synlett 2012, 23, 2631-2634. doi:10.1055/s-0032-1317477

6. Gholinejad, M. Appl. Organomet. Chem. 2013, 27, 19-22. doi:10.1002/aoc.2932

7. Singh, A. S.; Shendage, S. S.; Nagarkar, J. M. Tetrahedron Lett. 2013, 54, 6319-6323. doi:10.1016/j.tetlet.2013.09.027

8. El Bakouri, O.; Fernandez, M.; Brun, S.; Pla-Quintana, A.; Roglans, A. Tetrahedron 2013, 69, 9761-9765. doi:10.1016/j.tet.2013.09.010

9. Salabert, J.; Sebastian, R. M.; Vallribera, A.; Civicos, J. F.; Najera, C. Tetrahedron 2013, 69, 2655-2659. doi:10.1016/j.tet.2013.01.049

10. Filimonov, V. D.; Trusova, M. E.; Postnikov, P. S.; Krasnokutskaya, E. A.; Lee, Y. M.; Hwang, H. Y.; Kim, H.; Chi, K.-W. Org. Lett. 2008, 10, 3961-3964. doi:10.1021/ol8013528

11. Trusova, M. E.; Krasnokutskaya, E. A.; Postnikov, P. S.; Choi, Y.; Chi, K.-W.; Filimonov, V. D. Synthesis 2011, 2154-2158. doi:10.1055/s-0030-1260046

12. Kutonova, K. V.; Trusova, M. E.; Postnikov, P. S.; Filimonov, V. D.; Parello, J. Synthesis 2013, 45, 2706-2710. doi:10.1055/s-0033-1339648

13. Alonso, F.; Beletskaya, I. P.; Yus, M. Tetrahedron 2005, 61, 11771-11835. doi:10.1016/j.tet.2005.08.054

14. Chen, L.; Zhang, Y.; Kong, X.; Peng, S.; Tian, J. Bioorg. Med. Chem. Lett. 2007, 17, 2979-2982. doi:10.1016/j.bmcl.2007.03.068

15. Li, N.-G.; Wang, R.; Shi, Z.-H.; Tang, Y.-P.; Li, B.-Q.; Wang, Z.-J.; Song, S.-L.; Qian, L.-H.; Lo, W.; Yang, J.-P.; Yao, L.-J.; Xi, J.-Z.; Xu, J.; Feng, F.; Qian, D.-W.; Duan, J.-A. Drug Dev. Res. 2011, 72, 405-415. doi:10.1002/ddr.20442 
16. Li, W.; Li, N.; Tang, Y.; Li, B.; Liu, L.; Zhang, X.; Fu, H.; Duan, J. Bioorg. Med. Chem. Lett. 2012, 22, 6085-6088.

doi:10.1016/j.bmcl.2012.08.038

17. Wang, X.; Li, Y.; Zhao, Q.; Min, Z.; Zhang, C.; Lai, Y.; Ji, H.; Peng, S.; Zhang, Y. Org. Biomol. Chem. 2011, 9, 5670-5681.

doi:10.1039/c1ob05478c

18. Teodori, E.; Dei, S.; Garnier-Suillerot, A.; Gualtiari, F.; Manetti, D.; Martelli, C.; Romanelli, M. N.; Scapecchi, S.; Sudwan, P.; Salerno, M. J. Med. Chem. 2005, 48, 7426-7436. doi:10.1021/jm050542x

19. Qian, C. T.; Qiu, A. M.; Huang, Y. Z.; Chen, W. J. J. Organomet. Chem. 1991, 412, 53. doi:10.1016/0022-328X(91)86041-N

20. Liu, Y.; Zhang, Y. J. Chem. Res., Synop. 2002, 15-16. doi:10.3184/030823402103170493

\section{License and Terms}

This is an Open Access article under the terms of the Creative Commons Attribution License

(http://creativecommons.org/licenses/by/2.0), which permits unrestricted use, distribution, and reproduction in any medium, provided the original work is properly cited.

The license is subject to the Beilstein Journal of Organic Chemistry terms and conditions:

(http://www.beilstein-journals.org/bjoc)

The definitive version of this article is the electronic one which can be found at: doi:10.3762/bjoc. 11.41 